\title{
Role of Toll-like receptors in natural killer cell function in acute lymphoblastic leukemia (Review)
}

\author{
JANET GALLARDO-ZAPATA $^{1,2}$ and CARMEN MALDONADO-BERNAL ${ }^{1}$ \\ ${ }^{1}$ Immunology and Proteomics Research Unit, Children's Hospital of Mexico Federico Gómez, Mexico City 06720; \\ ${ }^{2}$ Faculty of Medicine, National Autonomous University of Mexico, Mexico City 04510, Mexico
}

Received August 22, 2020; Accepted December 22, 2020

DOI: 10.3892/ol.2021.13009

\begin{abstract}
Natural killer (NK) cells are specialized lymphocytes primarily involved in the response to infection and tumors. NK cells are characterized by the presence of specific surface molecules, as well as a wide repertoire of receptors that impart microenvironment-dependent effector functions. Among these receptors, Toll-like receptors (TLRs) can be activated to condition the NK response to either a cytotoxic or immunoregulatory phenotype. However, cellular function is frequently impaired during disorders such as cancer. In the last decade, it has become increasingly evident that the stimulation of NK cells is a requirement for their increased cytotoxic activity. TLR activation has been suggested as an alternative route for reestablishing the antitumor activity of NK cells. The present review summarizes the characteristics of NK cells, their receptors, the expression and function of NK cell TLRs, and their functional status in cancer, primarily acute lymphoblastic leukemia.
\end{abstract}

\section{Contents}

1. Overview of NK cells

2. Origin of NK cells

3. NK cell diversification

4. NK cell receptors

5. Toll-like receptor expression in NK cells

6. NK cells in cancer

7. NK cells in acute lymphoblastic leukemia

8. TLRs' importance against acute lymphoblastic leukemia

9. Conclusions

Correspondence to: Dr Carmen Maldonado-Bernal, Immunology and Proteomics Research Unit, Children's Hospital of Mexico Federico Gómez, 192 Calle Dr Márquez, Colonia Doctores, Mexico City 06720, Mexico

E-mail: cmaldobe@yahoo.com

Key words: natural killer cells, Toll-like receptors, acute lymphoblastic leukemia, cytotoxic phenotype, immunoregulatory phenotype

\section{Overview of NK cells}

Natural killer (NK) cells are considered to be a subpopulation of lymphocytic cells and, due to their granularity and size, are also regarded as long granular lymphocytes; however, NK cells are a morphologically homogeneous population indistinguishable from the total lymphocyte pool. NK cells constitute $5-15 \%$ of all mononuclear cells in the peripheral blood (1), and were initially thought to be generated only from CD34 ${ }^{+}$ lymphoid precursors in the bone marrow (2). However, studies in mice and humans suggest that NK cells are also able to develop and mature in secondary lymphoid tissues (3).

Phenotypically, NK cells are primarily identified by the expression of CD56 (neural cell adhesion molecule) (4) and CD16 (human IgG Fc receptor III, Fc $\gamma$ RIII), as well as the lack of CD3, T-cell receptors and CD19, typical of T and B lymphocytes (5). NK cells have recently been categorized as group 1 innate lymphoid cells, due to their ability to produce IFN- $\gamma$ and selectively express the T-box eomesodermin transcription factor, which is necessary for their development and function (6).

Functionally, NK cells play an important role in immunosurveillance, since they participate in innate resistance against infected cells without prior sensitization or antigenic presentation, and also exert natural cytotoxic activity against tumor cells (7). The activation of NK cells favors the maintenance of an inflammatory environment, since they produce a number of inflammatory cytokines that recruit other immune cells (8). Similarly, NK cells serve an important role in the expansion of Th1-type responses, and are involved in hematopoiesis-associated processes (9).

The existence of a population of memory NK cells has been suggested. However, despite evidence in non-human primates (10), this NK cell function has not yet been verified in humans, and requires further investigation (11).

\section{Origin of NK cells}

NK cells are derived from precursors that originate from hematopoietic stem cells in the bone marrow; when stimulated with interleukin (IL)-2, IL-15 and IL-7, these precursors develop into mature NK cells (12). However, these NK precursors (NKPs) can also originate from an early thymus lymphoid precursor (13). NKPs are able to circulate between different 
organs, maturing into functional NK cells in the bone marrow, thymus, liver, spleen and lymph nodes (12).

On reaching immune competence, NK cells leave their sites of origin and migrate to target tissues, including the lung, mucosa, intestine, liver, skin and uterus. At these sites, NK cells differentiate according to their resting or activated phenotypes, which express stimulation markers and exhibit unique functional properties (14).

\section{NK cell diversification}

Due to the various effector functions exhibited by NK cells in humans, the existence of subpopulations with specialized functions has been suggested. The use of monoclonal antibodies and flow cytometry has enabled the classification of NK cells according to the expression density of surface markers and their association with characteristic functions.

Based on the surface expression density of CD56, NK cells can be classified as 'bright', with high CD56 expression density, and 'dim', with low CD56 expression density. In the peripheral blood, $\sim 90 \%$ of NK cells are CD56 ${ }^{\mathrm{dim}}$, while the other $10 \%$ are CD56 $6^{\text {bright }}(15)$. Furthermore, according to the relative co-expression of CD56 and CD16, NK cells can also be classified into the following five subpopulations: i) $\mathrm{CD} 56^{\text {bright }} / \mathrm{CD} 16^{-}$, constituting $50-70 \%$ of the total $\mathrm{CD} 56^{\text {bright }}$ population; ii) $\mathrm{CD} 56^{\text {bright }} / \mathrm{CD}^{+} 6^{+}$, constituting $30-50 \%$ of total CD56 ${ }^{\text {bright }}$ cells; iii) CD56 $6^{\mathrm{dim}} / \mathrm{CD} 16^{-}$; iv) $\mathrm{CD} 56^{\mathrm{dim}} / \mathrm{CD} 16^{+}$; and v) $\mathrm{CD}^{\circ} / \mathrm{CD}^{\circ} 6^{+}(16)$. These populations detected in the blood of a healthy donor by flow cytometry (Appendix S1) are presented in Fig. 1.

CD56 ${ }^{\text {bright }} \mathrm{NK}$ cells are considered to be immunoregulatory, as they have the ability to secrete immunomodulatory cytokines such as IFN- $\gamma$, IL-10, IL-13, TNF- $\beta$ and granulocyte and monocyte colony stimulating factor at rest, with increased secretion following activation. However, the quantity and quality of these cytokines varies according to the stimulus, since interleukins such as IL-2, IL-15 and IL-18 are capable of increasing the secretion of IFN- $\gamma$, IL-10 and TNF- $\beta$ (17). NK CD56 ${ }^{\text {bright }}$ cells have a low density of perforin granules and granzymes, and exert decreased cytotoxic activity compared with CD56 ${ }^{\text {dim }}$ cells (18). Furthermore, CD56 ${ }^{\text {bright }}$ cells are the only NK cells that constitutively express the high-affinity IL-2 receptor, which is able to induce the proliferation of $\mathrm{NK}$ cells at low (picomolar) concentrations (19). CD56 $6^{\text {bright }}$ cells are also capable of proliferation and self-maintenance in the presence of IL-15, without co-stimulation (20).

The expression of adhesion molecules such as CD62L (L-selectin) (21), as well as chemokine receptors, namely C-C chemokine receptor type (CCR) 7, CCR4 and C-X-C chemokine receptor type (CXCR) 3, on the surface of CD56 $6^{\text {bright }}$ NK cells enables them to preferentially migrate to secondary lymphoid organs such as the tonsils and lymph nodes (22). Furthermore, the expression of CXCR 1 and CXCR 3 confers different migratory properties to CD56 $6^{\text {bright }}$ cells, causing them to be located primarily in the spleen and bone marrow, as well as at sites of acute inflammation (16).

CD56 $6^{\text {bright }} \mathrm{NK}$ cells have been suggested to be precursors of their CD56 ${ }^{\mathrm{dim}}$ counterparts as, under the influence of certain cytokines, the former can decrease their expression of CD56 and increase that of CD16 (23). Also, the CD56 ${ }^{\text {bright }}$ subpopulation is the first to appear during reconstitution of the immune system after bone marrow transplantation. In the $\mathrm{NK}^{\text {bright }}$ population, CD56 ${ }^{\text {bright }} / \mathrm{CD} 16^{-}$cells are considered immunomodulatory due to their interaction with dendritic cells in the lymph nodes, and elevated production of IFN- $\gamma$ (16). By contrast, the $\mathrm{CD} 56^{\text {bright }} / \mathrm{CD} 16^{+}$subpopulation is considered to be transitional, with minimal IL-2-induced proliferation and cytotoxic activity (24).

Approximately $90 \%$ of peripheral blood NK cells are $\mathrm{NK}^{\mathrm{dim}}$, of which the predominant phenotype is CD56 $6^{\mathrm{dim}} / \mathrm{CD} 16^{\text {bright }}(95 \%)$, with lower numbers of CD56 ${ }^{\mathrm{dim}} / \mathrm{CD} 16^{-}$and CD56\%CD16 ${ }^{\text {bright }}$ cells (16). Unlike their bright counterparts, $\mathrm{NK}^{\mathrm{dim}}$ cells are poor cytokine producers (17). However, when activated by contact with target cells, they are capable of producing IFN- $\gamma, \mathrm{TNF}-\alpha$, macrophage inflammatory protein (MIP)- $1 \alpha$ and MIP-1 $\beta$, sometimes in higher concentrations than those generated by CD56 ${ }^{\text {bright }}$ cells (8).

$\mathrm{NK}^{\mathrm{dim}}$ cells express low surface levels of the IL-2 receptor and, therefore, have little proliferative capacity in vitro, even when stimulated with high concentrations of IL-2 (19) and IL-15 (20). $\mathrm{NK}^{\mathrm{dim}}$ cells generally possess high cytotoxic activity due to their high expression levels of perforins, granzymes and cytolytic granules (25). Furthermore, $\mathrm{NK}^{\mathrm{dim}}$ cells express high quantities of receptors that enhance their ability to respond to abnormal cells, and a high surface density of CD16 that allows them to carry out antibody-mediated cytotoxicity functions (25).

Unlike CD8 T cells, the cytotoxic activity of NK cells against target cells does not require prior activation and is independent of the expression of major histocompatibility complex (MHC) molecules. This activity can be initiated by different processes, including degranulation and antibody-dependent cytotoxicity, as well as the binding of ligands to cellular death receptors (26).

The molecular mechanisms that regulate cellular cytotoxicity may be divided into three categories: i) Recognition of the target cell; ii) formation of the immune synapse; and iii) NK-induced cell death. Following recognition and the formation of the immune synapse, cell death is induced by two primary mechanisms (27). The first mechanism involves the activation of cell death receptors present on the surface of the target cell. These receptors include the TNF-related apoptosis-inducing ligand receptor (TRAIL-R) and Fas (CD95), which are activated by TRAIL and Fas ligand (CD95L), respectively (26). The stimulation of these receptors induces activation of the caspase 8 and 10 pathways, resulting in apoptotic cell death (28). However, the predominant mechanism of cytotoxicity involves the direct release of lytic granules towards the target cell. This requires reorganization of the cytoskeleton, as well as the polarization of NK cell microtubules. NK cells also contain perforins, enzymes that when integrated into the target cell membrane form a pore through which water can enter the cell, promoting osmotic lysis (29).

Granzyme B is a critical component of NK cells, as it is a protein capable of inducing apoptosis by promoting the breakdown of peptides with aspartic acid residues (26). Once inside the target cell, granzyme B induces caspase-dependent and -independent apoptosis, which is itself dependent on initiation by the direct cleavage of caspase 8 or 3 (30). 


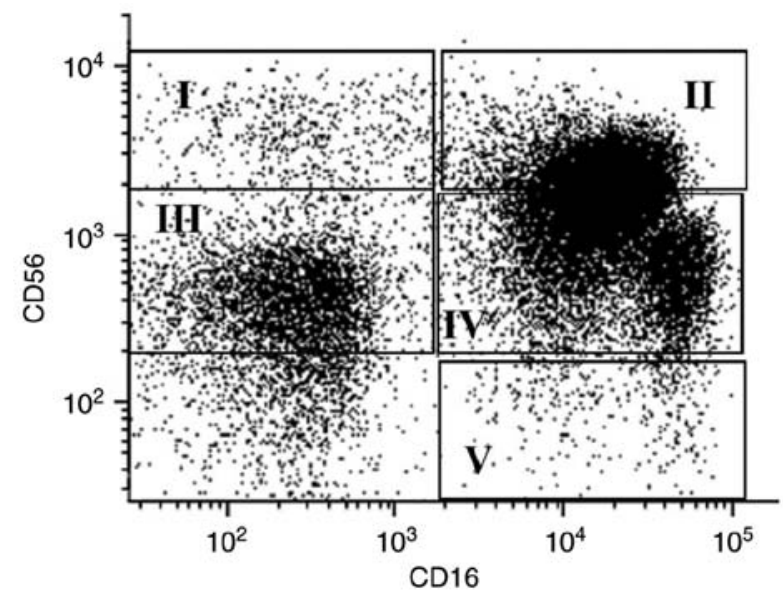

Figure 1. Flow cytometric analysis of CD56 $6^{\text {bright }}$ and CD56 ${ }^{\text {dim }}$ natural killer cell subpopulations from a healthy donor. (I) CD56 $6^{\text {bright }} / \mathrm{CD} 16^{\text {- }}$ (II) $\mathrm{CD}^{\text {bright }} / \mathrm{CD} 16^{+}$, (III) $\mathrm{CD}^{\mathrm{dim}} / \mathrm{CD} 16^{-}$, (IV) $\mathrm{CD}^{\mathrm{dim}} / \mathrm{CD} 16^{+}$and (V) $\mathrm{CD} 56^{-} / \mathrm{CD} 16^{+}$.

Caspase-independent apoptosis is achieved by the induction of cytochrome release from the mitochondria, and the cleavage of the pro-apoptotic protein Bid (31). These natural cytotoxic activities are reportedly most effectively by CD56 $6^{\mathrm{dim}} / \mathrm{CD} 16$ cells since upon activation, $\mathrm{CD} 56^{\mathrm{dim}} \mathrm{CD} 16^{\text {bright }}$ cells have been shown to lose their CD16 expression through metalloprotease-mediated cleavage to become CD56 ${ }^{\mathrm{dim}} \mathrm{CD} 16^{-}$, and express increased levels of CD107a, which has been described as a marker of degranulation (32).

As aforementioned, NK cells are capable of participating in antibody-mediated cytotoxicity, an immune mechanism by which NK cells induce the death of antibody-opsonized cells (33). Since CD56 ${ }^{\mathrm{dim}} / \mathrm{CD} 16^{\text {bright }} \mathrm{NK}$ cells express a high density of CD16, this subpopulation of $\mathrm{NK}^{\mathrm{dim}}$ cells is the most capable of performing this process (18). Once the target cell has been opsonized and CD16 recognizes the Fc region of immunoglobulins, cell death is induced by one of the aforementioned mechanisms (26).

\section{NK cell receptors}

NK cells express a variety of different receptors that allow them to interact with diverse cell subpopulations, and thus trigger different effector functions. Since NK cells do not express clonal receptors, the receptor repertoire of these cells comprises germline receptors, which have traditionally been classified as inhibitors or activators (15) (Fig. 2). These germline receptors include pattern recognition receptors (PRRs), which are discussed in more detail below.

The inhibitory receptors comprise two NK receptor superfamilies. The first family comprises the killer cell immunoglobulin-like receptors (KIRs) KIR2DL1-5 and KIR3DL1-3, which recognize classical MHC-I molecules. The other superfamily comprises lectin C-type receptors, which are heterodimers such as CD94/natural killer group 2 member A (NKG2A) that primarily recognize non-classical MHC molecules, including human leukocyte antigen (HLA)-E (34). When these receptors interact with their ligands, immunoreceptor tyrosine-based inhibitory motifs initiate signaling cascades that prevent NK-cell activation (35). NK cells also express subfamily B member 1 of the inhibitory leukocyte immunoglobulin-like receptor family (LILRB1), which binds non-classical MHC molecules such as HLA-G (36). Under physiological conditions, NK cells are inhibited by the interaction between the aforementioned receptors and their ligands, which are present on the surface of healthy cells. By contrast, when infected with intracellular pathogens or undergoing malignant transformation, cells frequently experience a reduction or loss of MHC-I expression, and therefore, become potential NK-cell targets. This phenomenon is known as missing self-recognition (37). However, the absence of MHC-I molecules on the surface of target cells is not sufficient to trigger the activation of NK cells, as the correct balance between inhibitory and activating receptor signals is required (38).

Activating receptors, such as KIR2DS, KIR3DS, NKG2D and NKG2E, are also capable of recognizing classical MHC-I molecules, while NKG2D receptors also bind non-classical MHC-I (36). These receptors possess immunoreceptor tyrosine-based activating motifs that transduce activation signals (39).

Furthermore, NK cells express natural cytotoxicity receptors, which are involved in the preferential activation of NK cells against tumor cells (15). Among these receptors, NKp30 (CD337) and NKp46 (CD335) are expressed by resting and activated NK cells, while NKp44 (CD336) is only expressed by activated NK cells (34).

NK cells also express co-stimulation ligands, including CD40L (CD154) (40) and OX40L, which allow them to impart co-stimulatory signals to T or B cells (41). Thus, NK cells serve as a bridge between innate and adaptive immunity. Dendritic cells stimulate NK cells to provide co-stimulatory signals to $\mathrm{T}$ or B cells, allowing for an optimal immune response (42).

Additionally, NK cells express PRRs through which they recognize pathogen-associated molecular patterns, as well as damage-associated molecular patterns (DAMPs). PRRs include Toll-like receptors (TLRs), NOD-like receptors (NLRs) (43) and RIG-I-like receptors (RLRs) (44). From the NLR family, NK cells have been shown to express NOD2 and NLRP3; when activated, these NLRs increase the cytotoxicity of NK cells against tumor cells, and upregulate the production of cytokines such as TNF- $\alpha$ and IFN- $\gamma$ (45). With respect to RLRs, NK cells have been shown to express RIG-I and melanoma differentiation-associated protein 5 receptors, which are of great importance in antiviral defense. These receptors have been shown to serve an important role in human NK-cell functioning, increasing their production of IFN- $\gamma$ as well as their antitumor activity (44).

Several studies have demonstrated the functional responses of human NK cells to stimulation with various TLR ligands $(46,47)$. The majority of studies indicate that NK cells require the concurrent presence of pro-inflammatory cytokines to respond to TLR agonists (48).

\section{Toll-like receptor expression in NK cells}

Initially, the identification of TLR expression in NK cells was based on mRNA detection only. In NK cells isolated from human peripheral blood, the constitutive expression of TLR1-8 mRNA 


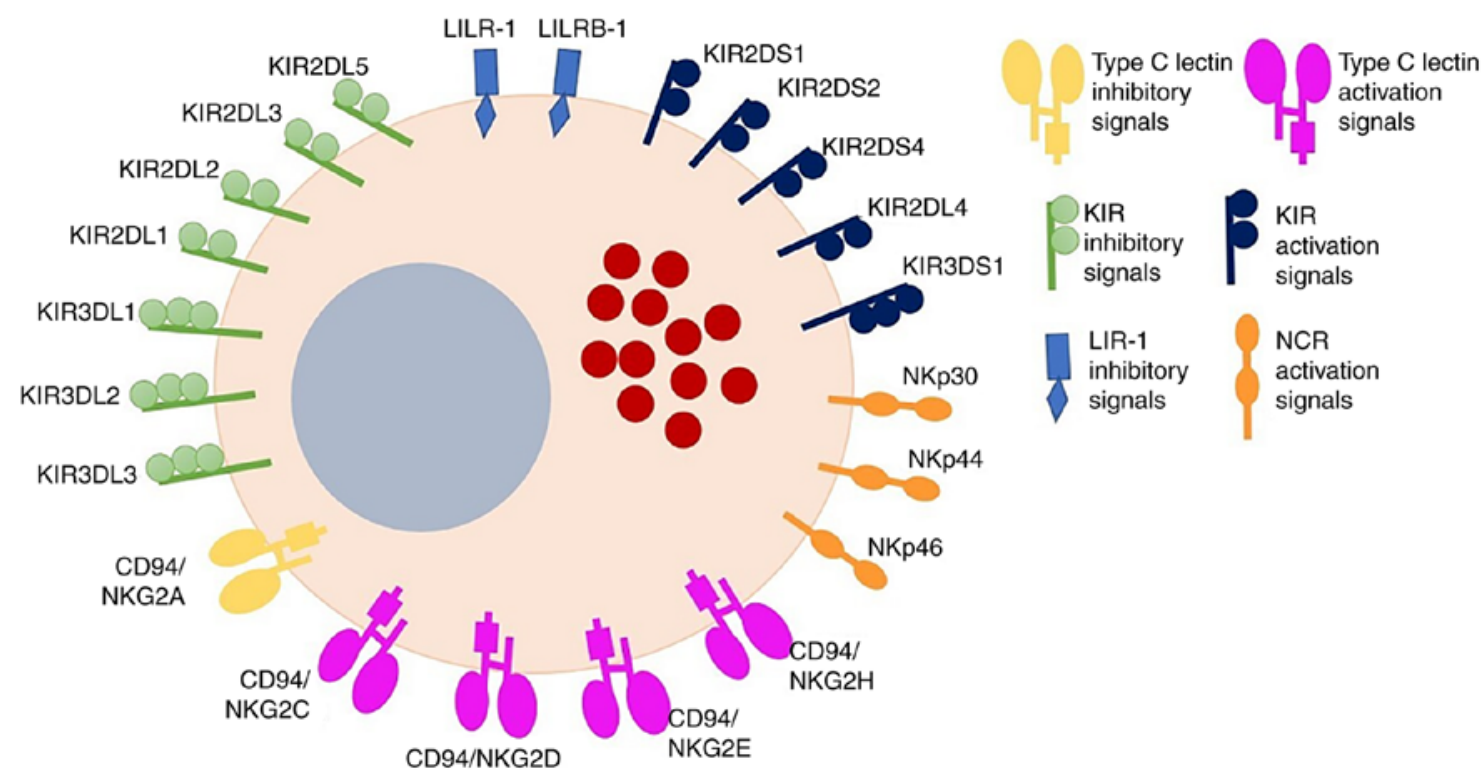

Figure 2. Inhibitory and activating NK-cell receptors, and the associated signals that are triggered subsequent to ligand-induced activation. NK, natural killer; KIR, killer cell immunoglobulin-like receptor; LIR-1, leukocyte immunoglobulin-like receptor 1; NCR, natural cytotoxicity receptor.

was observed, of which TLR2 and 3 were the most abundantly expressed. By contrast, the expression of TLR9 and 10 mRNA was found to be insignificant in CD56 ${ }^{\text {bright }}$ and CD56 ${ }^{\text {dim }} \mathrm{NK}$-cell populations (43). Furthermore, TLR2 mRNA was reported to be highly expressed, while TLR4 and 3 mRNAs were weakly expressed, and TLR8 $\mathrm{mRNA}$ was undetectable in resting human NK cells (49). Additionally, the mRNA levels of these four TLRs increased considerably following exposure to viral particles (49). In general, it has been observed that TLR2, 3, 5 and 6 are more frequently expressed than TLR4, 7, 8 and 9 by NK cells (50).

Regarding the responses generated by the activation of these TLRs, variations between different TLRs have been observed in NK cells in vitro and in samples from healthy donors. Becker et al (51) observed that when activated via TLR2, using lipophosphoglycan purified from leishmania, NK cells exhibited increased levels of IFN- $\gamma$, as well as the increased expression of cell surface TLR2. In 2004, Schmidt et al (52) determined that poly-inosinic-cytidylic acid [poly (I:C)] activates human NK cells via TLR3. In the same year, Sivori et al (53) demonstrated that TLR9 activation induces human NK cells to secrete IFN- $\gamma$ and TNF- $\alpha$.

Lauzon et al (50) revealed that human NK cells express TLR1-10 mRNA, and that the ligand binding of TLR2, 3, 5 and 9 stimulates the secretion of IFN- $\gamma$. In the same year, Gorski et al (54) concluded that TLR7 and 8 activation increases the production of IFN- $\gamma$ by human NK cells. In 2007, Alter et al (55) observed that TLR7 and 8 activation increased the production of pro-inflammatory cytokines by human NK cells from patients with HIV-1. In 2010, Mian et al (56) revealed that the production of IFN- $\gamma$ and TNF- $\alpha$ was increased via TLR4 activation in humans and mice, and in 2013, He et al (57) demonstrated that human and mouse NK cells could be activated via the binding of TLR1 with several miRNAs.

These observations are generalized throughout the NK subpopulations. However, relative TLR expression varies according to NK-cell phenotype. For example, TLR2 is preferentially expressed by CD56 $6^{\text {bright }} \mathrm{NK}$ cells, and TLR3 by CD56 ${ }^{\mathrm{dim}}$ cells $(48,58)$. These variations suggest that stimulation with TLR ligands imparts a cytotoxic or immunomodulatory response, depending on the ligand.

The knowledge that TLRs are expressed by NK cells (Fig. 3) has increased interest in their immune response against viral and bacterial infections, as well as their antitumor activity. However, it has been observed that the DAMP-induced activation of NK cells can only occur via complex interaction with other cells of the immune system and within the cellular microenvironment (59).

\section{NK cells in cancer}

As aforementioned, NK cells are the primary mediators of immunosurveillance against tumor cells (60), as they can detect changes in the expression of MHC-I molecules and eliminate cells that have undergone malignant transformation (29). Mutations that arise during malignant transformation are reflected via alterations in MHC-I expression (61), as well as the overexpression of stress molecules that can be recognized by NKG2D receptors (62). However, neoplastic cells use various mechanisms to evade antitumor activity. In an 11-year follow-up study, an association was found between the low cytotoxicity of peripheral blood NK cells and an increased risk of cancer (63). Although the infiltration of NK cells has been shown to favor tumor elimination in various carcinomas, including colorectal (64), gastric (65) and lung cancers (66), these cells are found in small quantities within the tumor (67) and exhibit changes in the expression of activating receptors (68); additionally, the tumor microenvironment favors immunosuppression $(69,70)$, which may also explain the small number of NK cells found within the tumor itself.

\section{NK cells in acute lymphoblastic leukemia}

With regard to hematological cancers such as leukemia, little is known of how these disorders affect the origination of NK 


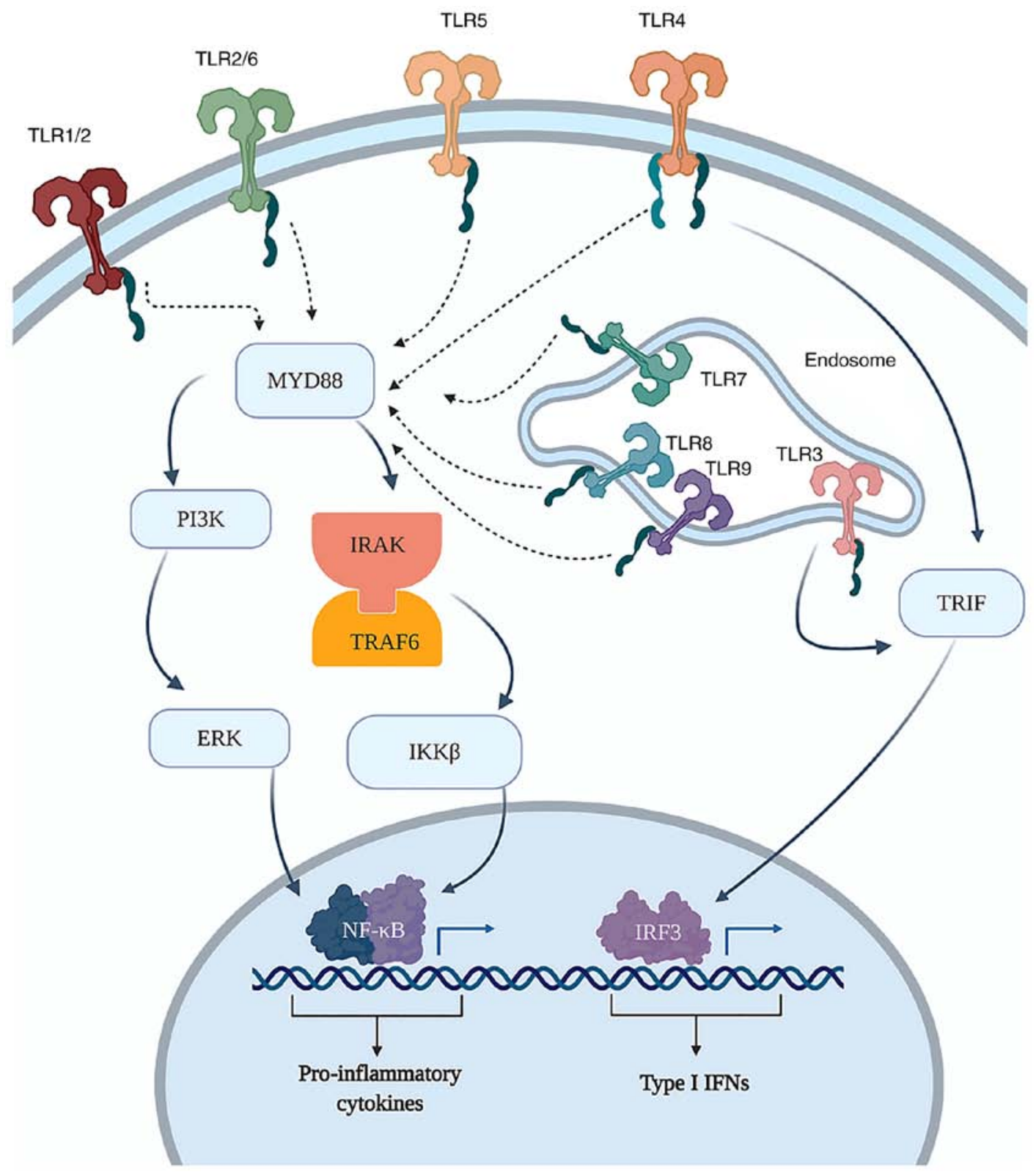

Figure 3. TLRs and their post-activation signals in NK cells based on observations in cells from healthy donors. NK, natural killer; TLR, Toll-like receptor; IRAK, interleukin-1 receptor associated kinase; TRAF6, TNF receptor-associated factor 6; TRIF, TIR-domain-containing adapter-inducing interferon- $\beta$; IRF3, interferon regulatory factor 3 .

cells, since both the neoplasia and NK cells originate from the bone marrow. On the basis of studies of patients with chronic myeloid leukemia (71,72), impaired or abnormal NK-mediated cytotoxicity, as well as the aberrant expression of NK receptors, constitute fundamental factors in the progression of the neoplasm (73).

A study of NK cells in the peripheral blood of patients when diagnosed with acute lymphoblastic leukemia (ALL) type B revealed that they exhibit TGF- $\beta 1$-mediated compromised cytotoxicity towards K562 cells and autologous blasts. Furthermore, the NK cells were found to have an inhibitory phenotype, represented by altered cell surface expression of NKp46 and NKG2A, compared with those from healthy control subjects of the same age (74). The study also demonstrated that after remission, NK cell-mediated cytotoxicity towards K562 was recovered, but not that towards autologous blasts, suggesting that blasts undergo successful immune editing (74).

A recent study in Mexican patients with ALL reported a reduction in the percentage of NK cells at diagnosis, as well as impaired cytotoxicity in patients with B- and T-ALL (75). Furthermore, in B-ALL, NK cell-mediated cytotoxicity in patients with leukocyte counts of $>50,000 / \mathrm{mm}^{3}$ was observed to be impaired compared with that in cases with lower counts. These data suggest that the abnormal effector function of NK cells is not observed equally in all pediatric patients with B-ALL, and that there may be other contributing factors to NK cell-mediated cytotoxicity (75).

Chemotherapeutics against leukemia have been shown to decrease the number and activity of NK cells during treatment. However, upon the discontinuation of treatment, it is possible that normal NK-cell levels slowly recover, although their 


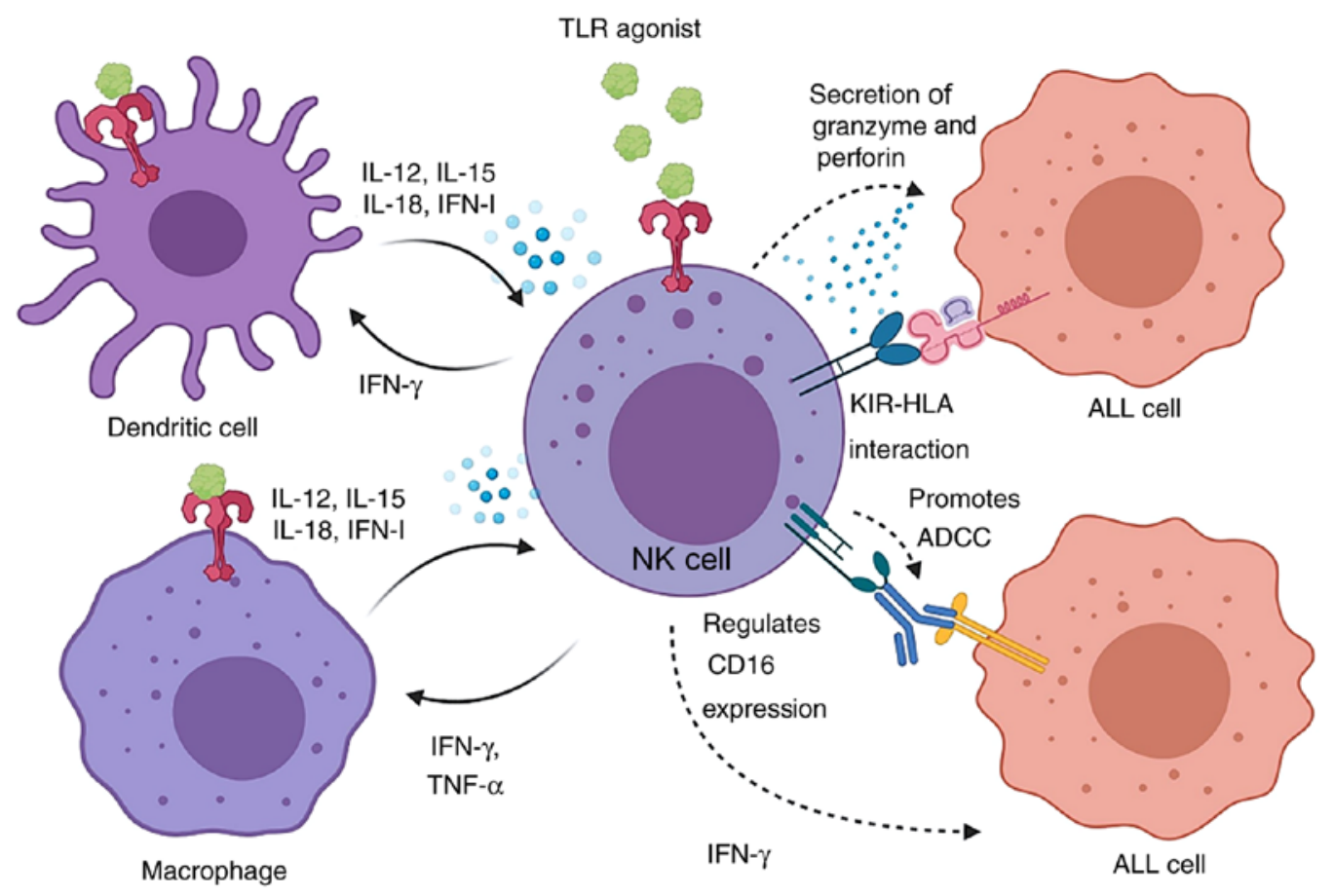

Figure 4. NK-cell activation through TLRs may trigger and enhance different mechanisms to attack to cells in ALL. The dotted arrows indicate hypothetical mechanisms, as they have been observed for NK cells with PBMCs not cancer cells. Mechanisms are based on observations from research on donor PBMC/NK cells treated with TLRs. NK, natural killer; TLR, Toll-like receptor; ALL, acute lymphoblastic leukemia; PBMC, peripheral blood mononuclear cell; IL, interleukin; ADCC, antibody-dependent cytotoxicity; KIR, killer cell immunoglobulin-like receptor; HLA, human leukocyte antigen.

cytotoxicity does not (76). Evidence of the importance of NK cells in tumor regulation has primarily been based on clinical studies of patients with leukemia who have undergone allogeneic hematopoietic stem cell transplantation (cell therapy) (77). This is a safe therapy, which avoids graft-vs.-host rejection disease (GvHD) (78).

Cellular immunotherapy, also known as adoptive cell therapy, has been accomplished by the use of engineered cells, among which chimeric antigenic receptor T (CAR-T) cells have achieved successful outcomes for B-cell lymphoblastic leukemia; a cohort study revealed that a single infusion of this therapy provided durable remission with long-term persistence in pediatric and young adult patients with relapsed or refractory B-cell ALL (79). However, the application of CAR-T cells has faced obstacles, two of which are: Patients who experience low CAR-T cell persistence or disease relapse cannot be reinfused with CAR-T cells; and the majority of patients experience cytotoxic effects (80). The development of CAR-NK cells could be an attractive solution to those issues.

As NK cells lack T-cell receptors that could cause GvHD and do not require HLA matching to be cytotoxic, CAR-NK cells have potential as cellular therapeutics. Pre-clinical studies with CAR-expressing NK cells have focused on anti-CD19 and anti-CD20 CARs targeting B cell malignancies, and have observed that CAR-NK cells are capable of increasing IFN- $\gamma$ expression in response to $\mathrm{CD} 19^{+}$cells as well as increasing their specific cytotoxicity in xenograft models of B-ALL $(81,82)$.

Despite their advantages over CAR T cells, CAR-NK cell-based therapies have made limited clinical progress (83). Currently, there are 19 studies registered in the clinicaltrials. gov database for the use of CAR-NK cells in patients with cancer; 12 are trials in phase I/II that are recruiting, and two have already been completed. In the majority of these trials, the CAR-NK cells target CD19, CD22, CD33 or CD7 on hematopoietic malignancies (83).

The first large-scale trial of CAR-NK cells used CAR-NK cells derived from cord blood to treat high-risk CD19 ${ }^{+} \mathrm{B}$ cell malignancies (84). An anti-CD19-CD28-CD3ఢ CAR was used for transduction of the cells, in addition to an IL-15 gene and inducible caspase 9 as a safety switch. In that study, 7/11 patients achieved complete remission, and showed an early expansion of CAR-NK cells compared with the non-responders. This response was achieved with no serious side effects, such as cytokine release syndrome, neurotoxicity and GvHD, even in the 5 patients with a KIR-ligand mismatch (84). Overall, the study demonstrated the initial efficacy and safety profile of this CAR-NK cell therapy. Although CAR-NK cells have multiple advantages compared with CAR-T cells, they have several challenges to overcome, such as loss of targeted antigen and tumor heterogeneity (83). Therefore, novel strategies should be sought to optimize the efficacy of CAR-based NK cell therapy.

\section{TLRs' importance against acute lymphoblastic leukemia}

Considering that poor cytotoxic activity of NK cells suggests an alteration in their activation, immunological strategies designed to improve the sensitivity of neoplastic cells to NK cell-mediated cytotoxicity should focus on the mechanisms by which NK cells are activated. Such mechanisms include the use of specific TLR ligands to restore NK-cell activation and cytotoxicity.

However, little information is available regarding the possibility of reactivating or modulating the functions of $\mathrm{NK}$ 
cells in vivo. Although ligands exist for the stimulation of these receptors in vitro, it is not yet known with certainty whether they can be used as therapeutic agents in leukemia, where a reduction in the expression of TLRs has been reported in peripheral blood mononuclear cells (85).

A preclinical study demonstrated that TLR ligands can effectively activate donor NK cells to induce blast lysis (86). Therefore, they have been suggested as potential boosters for stimulating the immunological effector function of NK cells in leukemia immunotherapy. Among these ligands, the TLR3 agonist poly (I:C) demonstrated the ability to activate NK cells in vivo, and improved the therapeutic activity of a monoclonal antibody against human CD7 in a xenograft model of T-ALL (87). The TLR3 agonist was also demonstrated to cause changes in the expression levels of CD2, CD16/32 (FcRII/RIII), CD161 (NK1.1) and F4/80 in the host splenocyte population. It was suggested that the mechanism underling the boost in NK cells following their activation via TLR3 in the ALL model is antibody-dependent cytotoxicity (ADCC), based on the previous observation that when cancer cells are coated by an antibody, the cell lysis is increased compared with that of cells not coated with antibody (87).

There is evidence that the TLR7 agonist R848 can boost the efficacy of obinutuzumab in CD-20+ lymphoma, since it has been shown to enhance non-specific NK-cell cytotoxicity (88). Since R848 and other TLR7 agonists can raise the levels of activating $\mathrm{Fc} \gamma \mathrm{R}$ and reduce those inhibitory $\mathrm{Fc} \gamma \mathrm{RIIb}$, this supports the suggestion that R848 triggers ADCC as an effector mechanism. Notably, the interaction of NK cells with R848 in vivo induced the production of IFN- $\gamma$ by the NK cells upon engagement of the Fc receptors by obinutuzumab. Furthermore, the study demonstrated that the systemic administration of R848 combined with obinutuzumab therapy enhanced the long-term survival of patients with lymphoma (88). A more recent study with an encapsulated TLR7/8 agonist also demonstrated positive immunotherapeutic effects, since strong in vivo cytotoxicity against the K562 leukemia cell line was achieved through NK degranulation and the release of granzyme B, and the activation of NK cells was prolonged. In addition, the TLR7/8 agonist enhanced the in vitro and in vivo ADCC of the epidermal growth factor receptor-targeting antibody cetuximab. These findings indicate the potential of the TLR7/8 agonist as a potent immunostimulatory adjuvant for antibody-based cancer immunotherapy, which acts via the promotion of NK-cell activation (89).

Although the aforementioned studies confirm that it is possible to activate NK cells through their TLRs to favor the lysis of carcinogenic cells, it is not yet possible to affirm the effects of this method in NK cells from hematological disorders such as ALL. Although there are existing clinical trials evaluating the effects of TLR stimulation on leukemia, with the clinicaltrials.gov database listing four completed clinical trials and two in the recruitment phase, only one of these has been performed in patients with ALL, with one NK-associated observation (90). This trial, reported by Ronsley et al (90), was a phase I pilot study, in which the regulatory effect of the TLR9 ligand GNKG168 on various genes was evaluated in three pediatric patients with ALL with residual disease following conventional therapy. GNKG168 was concluded to induce immunological changes in the mononuclear cells of patients via the negative regulation of genes (mRNAs) that participate in the antitumor response, such as single Ig and TIR domain containing, IL-1 receptor ligand 1, CCR8, IL-7 receptor (IL7R), CD8B and CD3D. These findings suggest that inhibiting IL7R may also act as a checkpoint inhibitor of IL7R expression in the CD56 ${ }^{\text {bright }} \mathrm{NK}$ population, which is important for modulating the post-transplant response.

\section{Conclusions}

NK cells play an important role in the antitumor response. Due to the discovery that TLRs can induce the cytotoxicity and cytokine production of NK cells, TLR agonists have been proposed as potential stimulators of the antitumor effector functions of NK cells. However, further studies are required to elucidate the antitumor effects of NK cells, and understand the activation mechanisms of TLRs therein, in order to improve NK cell-mediated immunotherapy.

\section{Acknowledgements}

Not applicable.

\section{Funding}

Children's Hospital of Mexico Federico Gómez (grant no. HIM/2019/035 SSA 1618).

\section{Availability of data and materials}

The datasets used and/or analyzed during the current study are available from the corresponding author on reasonable request.

\section{Authors' contributions}

JGZ reviewed the literature and prepared drafts of the manuscript. CMB assisted in evaluation of the literature and finalizing manuscript for submission. All authors have read and approved the final version of this manuscript.

\section{Ethics approval and consent to participate}

The study was ethically approved by the Research, Research Ethics and Biosafety Committees of the Children's Hospital of Mexico Federico Gómez (protocol no. HIM/2019/035). Patient consent was not required because waste blood from the blood bank of the Children's Hospital of Mexico Federico Gomez was used.

\section{Patient consent for publication}

Not applicable.

\section{Competing interests}

The authors declare that they have no competing interests.

\section{References}

1. Timonen BYT, Ortaldo JR and Herberman RB: Characteristics of human large granular lymphocytes and relationship to natural killer and K cells. J Exp Med 153: 569-582, 1981. 
2. Galy A, Travis M, Cen D and Chen B: Human T, B, natural killer, and dendritic cells arise from a common bone marrow progenitor cell subset. Immunity 3: 459-473, 1995.

3. Scoville SD, Freud AG and Caligiuri MA: Modeling human natural killer cell development in the era of innate lymphoid cells. Front Immunol 8: 360, 2017.

4. Nitta T, Yagita H, Sato K and Okumura K: Involvement of CD56 (NKH-1/Leu-19 antigen) as an adhesion molecule in natural killer-target cell interaction. J Exp Med 170: 1757-1761, 1989.

5. Lanier LL, Le AM, Civin CI, Loken MR and Phillips JH: The relationship of CD16 (Leu-11) and Leu-19 (NKH-1) antigen expression on human peripheral blood NK cells and cytotoxic T lymphocytes. J Immunol 136: 4480-4486, 1986.

6. Vivier E, Artis D, Colonna M, Diefenbach A, Di Santo JP, Eberl G, Koyasu S, Locksley RM, McKenzie ANJ, Mebius RE, et al: Innate lymphoid cells: 10 years on. Cell 174: 1054-1066, 2018.

7. Chiorean EG and Miller JS: The biology of natural killer cells and implications for therapy of human disease. J Hematotherapy Stem Cell Res 10: 451-463, 2001.

8. Fauriat C, Long EO, Ljunggren HG and Bryceson YT: Regulation of human NK-cell cytokine and chemokine production by target cell recognition. Blood 115: 2167-2176, 2010.

9. Lotze MT and Thomson AW: Natural killer cells: Basic science and clinical application. Academic Press, 2009.

10. Reeves RK, Li H, Jost S, Blass E, Li H, Schafer JL, Varner V, Manickam C, Eslamizar L, Altfeld M, et al: Antigen-specific NK cell memory in rhesus macaques. Nat Immunol 16: 927-932, 2015 .

11. Nikzad R, Angelo LS, Aviles-Padilla K, Le DT, Singh VK, Bimler L, Vukmanovic-Stejic M, Vendrame E, Ranganath T, Simpson L, et al: Human natural killer cells mediate adaptive immunity to viral antigens. Sci Immunol 4: eaat8116, 2019.

12. Freud AG, Yokohama A, Becknell B, Lee MT, Mao HC Ferketich AK and Caligiuri MA: Evidence for discrete stages of human natural killer cell differentiation in vivo. J Exp Med 203 1033-1043, 2006.

13. Rosmaraki EE, Douagi I, Roth C, Colucci F, Cumano A and Di Santo JP: Identification of committed NK cell progenitors in adult murine bone marrow. Eur J Immunol 31: 1900-1909, 2001.

14. Huntington ND, Vosshenrich CAJ and Di Santo JP: Developmental pathways that generate natural-killer-cell diversity in mice and humans. Nat Rev Immunol 7: 703-714, 2007.

15. Cooper MA, Fehniger TA and Caligiuri MA: The biology of human natural killer-cell subsets. Trends Immunol 22: 633-640, 2001.

16. Poli A, Michel T, Thérésine $M$, Andrès E, Hentges $F$ and Zimmer J: CD56bright natural killer (NK) cells: An important NK cell subset. Immunology 126: 458-465, 2009.

17. Cooper MA, Fehniger TA, Turner SC, Chen KS, Ghaheri BA, Carson WE and Caligiuri MA: Human natural killer cells: A unique innate immunoregulatory role for the CD56bright subset. Blood 96: 3146-3151, 2000.

18. Nagler A, Lanier LL, Cwirla S and Phillips JH: Comparative studies of human FcRIII-positive and negative natural killer cells. J Immunol 143: 3183-3191, 1989.

19. Caligiuri MA, Murray C, Robertson MJ, Wang E, Cochran K, Cameron C, Schow P, Ross ME, Klumpp TR, Soiffer RJ, et al: Selective modulation of human natural killer cells in vivo after prolonged infusion of low dose recombinant interleukin 2. J Clin Invest 91: 123-132, 1993.

20. Mrózek E, Anderson P and Caligiuri MA: Role of interleukin-15 in the development of human CD56+ natural killer cells from CD34+ hematopoietic progenitor cells. Blood 87: 2632-2640, 1996.

21. Frey M, Packianathan NB, Fehniger TA, Ross ME, Wang WC, Stewart CC, Caligiuri MA and Evans SS: Differential expression and function of L-selectin on CD56bright and CD56dim natural killer cell subsets. J Immunol 161: 400-408, 1998.

22. Berahovich RD, Lai NL, Wei Z, Lanier LL and Schall TJ Evidence for NK cell subsets based on chemokine receptor expression. J Immunol 177: 7833-7840, 2006.

23. Chan A, Hong DL, Atzberger A, Kollnberger S, Filer AD, Buckley CD, McMichael A, Enver T and Bowness P: CD56bright human NK cells differentiate into CD56dim cells: Role of contact with peripheral fibroblasts. J Immunol 179: 89-94, 2007.

24. Béziat V, Duffy D, Quoc SN, Le Garff-Tavernier M, Decocq J, Combadière B, Debré $\mathrm{P}$ and Vieillard V: CD56brightCD16+ NK cells: A functional intermediate stage of NK cell differentiation. J Immunol 186: 6753-6761, 2011.
25. Vivier E, Tomasello E, Baratin M, Walzer T and Ugolini S: Functions of natural killer cells. Nat Immunol 9: 503-510, 2008.

26. Smyth MJ, Cretney E, Kelly JM, Westwood JA, Street SE, Yagita H, Takeda K, van Dommelen SL, Degli-Esposti MA and Hayakawa Y: Activation of NK cell cytotoxicity. Mo Immunol 42: 501-510, 2005.

27. Krzewski K and Strominger JL: The killer's kiss: The many functions of NK cell immunological synapses. Curr Opin Cell Biol 20: 597-605, 2008

28. Guicciardi ME and Gores GJ: Life and death by death receptors. FASEB J 23: 1625-1637, 2009.

29. Abel AM, Yang C, Thakar MS and Malarkannan S: Natural killer cells: Development, maturation, and clinical utilization. Front Immunol 9: 1-23, 2018.

30. Barry M, Heibein JA, Pinkoski MJ, Lee SF, Moyer RW, Green DR and Bleackley RC: Granzyme B short-circuits the need for caspase 8 activity during granule-mediated cytotoxic T-lymphocyte killing by directly cleaving Bid. Mol Cell Biol 20: 3781-3794, 2000

31. Pinkoski MJ, Waterhouse NJ, Heibein JA, Wolf BB, Kuwana T, Goldstein JC, Newmeyer DD, Bleackley RC and Green DR: Granzyme B-mediated apoptosis proceeds predominantly through a Bcl-2-inhibitable mitochondrial pathway. J Biol Chem 276: 12060-12067, 2001

32. Amand M, Iserentant G, Poli A, Sleiman M, Fievez V, Sanchez IP, Sauvageot N, Michel T, Aouali N, Janji B, et al: Human CD56 ${ }^{\mathrm{dim}} \mathrm{CD} 16^{\mathrm{dim}}$ cells as an individualized natural killer cell subset. Front Immunol 8: 699, 2017.

33. Iannello A and Ahmad A: Role of antibody-dependent cell-mediated cytotoxicity in the efficacy of therapeutic anti-cancer monoclonal antibodies. Cancer Metastasis Rev 24: 487-499, 2005.

34. Zambello R, Falco M, Della Chiesa M, Trentin L, Carollo D, Castriconi R, Cannas G, Carlomagno S, Cabrelle A, Lamy T, et al: Expression and function of KIR and natural cytotoxicity receptors in NK-type lymphoproliferative diseases of granular lymphocytes. Blood 102: 1797-1805, 2003.

35. Bryceson YT, March ME, Ljunggren HG and Long EO: Activation, coactivation, and costimulation of resting human natural killer cells. Immunol Rev 214: 73-91, 2006.

36. Li NL, Davidson CL, Humar A and Burshtyn DN: Modulation of the inhibitory receptor leukocyte Ig-like receptor 1 on human natural killer cells. Front Immunol 2: 46, 2011.

37. Ljunggren HG and Kärre K: In search of the 'missing self': MHC molecules and NK cell recognition. Immunol Today 11: 237-244, 1990.

38. Tomasello E, Blery M, Vely E and Vivier E: Signaling pathways engaged by NK cell receptors: Double concerto for activating receptors, inhibitory receptors and NK cells. Semin Immunol 12: 139-147, 2000.

39. Lanier LL: Up on the tightrope: Natural killer cell activation and inhibition. Nat Immunol 9: 495-502, 2008.

40. Blanca IR, Bere EW, Young HA and Ortaldo JR: Human B cell activation by autologous NK cells is regulated by CD40-CD40 ligand interaction: Role of memory B cells and CD5+ B cells. J Immunol 167: 6132-6139, 2001.

41. Zingoni A, Sornasse T, Cocks BG, Tanaka Y, Santoni A and Lanier LL: Cross-talk between activated human NK cells and CD4+ T cells via OX40-OX40 ligand interactions. J Immunol 173: 3716-3724, 2004

42. Orange JS and Ballas ZK: Natural killer cells in human health and disease. Clin Immunol 118: 1-10, 2006.

43. Chalifour A, Jeannin P, Gauchat JF, Blaecke A, Malissard M, N'Guyen T, Thieblemont N and Delneste Y: Direct bacterial protein PAMP recognition by human NK cells involves TLRs and triggers $\alpha$-defensin production. Blood 104: 1778-1783, 2004

44. Perrot I, Deauvieau F, Massacrier C, Hughes N, Garrone P, Durand I, Demaria O, Viaud N, Gauthier L, Blery M, et al: TLR3 and Rig-like receptor on myeloid dendritic cells and Rig-like receptor on human NK cells are both mandatory for production of IFN-gamma in response to double-stranded RNA. J Immunol 185: 2080-2088, 2010.

45. Qiu F, Maniar A, Quevedo Diaz M, Chapoval AI and Medvedev AE: Activation of cytokine-producing and antitumor activities of natural killer cells and macrophages by engagement of Toll-like and NOD-like receptors. Innate Immun 17: 375-387, 2011.

46. Sivori S, Carlomagno S, Moretta L and Moretta A: Comparison of different $\mathrm{CpG}$ oligodeoxynucleotide classes for their capability to stimulate human NK cells. Eur J Immunol 36: 961-967, 2006. 
47. Girart MV, Fuertes MB, Domaica CI, Rossi LE and Zwirner NW: Engagement of TLR3, TLR7, and NKG2D regulate IFN-gamma secretion but not NKG2D-mediated cytotoxicity by human NK cells stimulated with suboptimal doses of IL-12. J Immunol 179: 3472-3479, 2007.

48. Sivori S, Carlomagno S, Pesce S, Moretta A, Vitale M and Marcenaro E: TLR/NCR/KIR: Which one to use and when? Front Immunol 5: 105, 2014.

49. Saikh KU, Lee JS, Kissner TL, Dyas B and Ulrich RG: Toll-like receptor and cytokine expression patterns of CD56+ T cells are similar to natural killer cells in response to infection with Venezuelan equine encephalitis virus replicons. J Infect Dis 188: 1562-1570, 2003.

50. Lauzon NM, Mian F, MacKenzie R and Ashkar AA: The direct effects of Toll-like receptor ligands on human NK cell cytokine production and cytotoxicity. Cell Immunol 241: 102-112, 2006.

51. Becker I, Salaiza N, Aguirre M, Delgado J, Carrillo-Carrasco N, Kobeh LG, Ruiz A, Cervantes R, Torres AP, Cabrera N, et al: Leishmania lipophosphoglycan (LPG) activates NK cells through toll-like receptor-2. Mol Biochem Parasitol 130: 65-74, 2003.

52. Schmidt KN, Leung B, Kwong M, Zarember KA, Satyal S, Navas TA, Wang F and Godowski PJ: APC-independent activation of NK cells by the toll-like receptor 3 agonist double-stranded RNA. J Immunol 172: 138-143, 2004.

53. Sivori S, Falco M, Della Chiesa M, Carlomagno S, Vitale M, Moretta L and Moretta A: CpG and double-stranded RNA trigger human NK cells by toll-like receptors: Induction of cytokine release and cytotoxicity against tumors dendritic cells. Proc Nat Acad Sci USA 101: 10116-10121, 2004.

54. Gorski KS, Waller EL, Bjornton-Severson J, Hanten JA, Riter CL, Kieper WC, Gorden KB, Miller JS, Vasilakos JP, Tomai MA and Alkan SS: Distinct indirect pathways govern human NK-cell activation by TLR-7 and TLR- 8 agonists. Int Immunol 18 : $1115-1126,2006$

55. Alter G, Suscovich TJ, Teigen N, Meier A, Streeck H, Brander C and Altfeld M: Single-stranded RNA derived from HIV-1 serves as a potent activator of NK cells. J Immunol 178: 7658-7666, 2007

56. Mian MF, Lauzon NM, Andrews DW, Lichty BD and Ashkar AA FimH can directly activate human and murine natural killer cells via TLR4. Mol Ther 18: 1379-1388, 2010.

57. He S, Chu J, Wu LC, Mao H, Peng Y, Alvarez-Breckenridge CA Hughes T, Wei M, Zhang J, Yuan S, et al: MicroRNAs activate natural killer cells through Toll-like receptor signaling. Blood 121: 4663-4671, 2013

58. Guo Q and Zhang C: Critical role of Toll-like receptor signaling in NK cell activation. Chinese Sci Bull 57: 3192-3202, 2012

59. Adib-Conquy M, Scott-Algara D, Cavaillon JM and Souza-Fonseca-Guimaraes F: TLR-mediated activation of NK cells and their role in bacterial/viral immune responses in mammals. Immunol Cell Biol 92: 256-262, 2014

60. Ljunggren HG and Malmberg KJ: Prospects for the use of NK cells in immunotherapy of human cancer. Nat Rev Immunol 7: 329-339, 2007.

61. Algarra I, García-Lora A, Cabrera T, Ruiz-Cabello F and Garrido F: The selection of tumor variants with altered expression of classical and nonclassical MHC class I molecules: Implications for tumor immune escape. Cancer Immunol Immunother 53: 904-910, 2004.

62. Samarakoon A, Chu H and Malarkannan S: Murine NKG2D ligands:'Double, double toil and trouble.' Mol Immunol 46 : 1011-1019, 2009.

63. Imai K, Matsuyama S, Miyake S, Suga K and Nakachi K: Natural cytotoxic activity of peripheral-blood lymphocytes and cancer incidence: An 11-year follow-up study of a general population. Lancet 356: 1795-1799, 2000.

64. Coca S, Perez-Piqueras J, Martinez D, Colmenarejo A, Saez MA, Vallejo C, Martos JA and Moreno M: The prognostic significance of intratumoral natural killer cells in patients with colorectal carcinoma. Cancer 79: 2320-2328, 1997.

65. Ishigami $S$, Natsugoe $S$, Tokuda K, Nakajo A, Che X, Iwashige $H$ Aridome K, Hokita S and Aikou T: Prognostic value of intratumoral natural killer cells in gastric carcinoma. Cancer 88 $577-583,2000$.

66. Villegas FR, Coca S, Villarrubia VG, Jiménez R, Chillón MJ, Jareño J, Zuil M and Callol L: Prognostic significance of tumor infiltrating natural killer cells subset CD57 in patients with squamous cell lung cancer. Lung Cancer 35: 23-28, 2002.

67. Habif G, Crinier A, André P, Vivier E and Narni-Mancinelli E. Targeting natural killer cells in solid tumors. Cell Mol Immunol 16: 415-422, 2019.
68. Guillerey C, Huntington ND and Smyth MJ: Targeting natural killer cells in cancer immunotherapy. Nat Immunol 17: 1025-1036, 2016

69. Vitale M, Cantoni C, Pietra G, Mingari MC and Moretta L: Effect of tumor cells and tumor microenvironment on NK-cell function. Eur J Immunol 44: 1582-1592, 2014.

70. Mushtaq MU, Papadas A, Pagenkopf A, Flietner E, Morrow Z, Chaudhary SG and Asimakopoulos F: Tumor matrix remodeling and novel immunotherapies: The promise of matrix-derived immune biomarkers. J Immunother Cancer 6: 65, 2018.

71. Diermayr S, Himmelreich H, Durovic B, Mathys-Schneeberger A, Siegler U, Langenkamp U, Hofsteenge J, Gratwohl A, Tichelli A, Paluszewska M, et al: NKG2D ligand expression in AML increases in response to HDAC inhibitor valproic acid and contributes to allorecognition by NK-cell lines with single KIR-HLA class I specificities. Blood 111: 1428-1436, 2008.

72. Chang MC, Cheng HI, Hsu K, Hsu YN, Kao CW, Chang YF, Lim KH and Chen CG: NKG2A down-regulation by dasatinib enhances natural killer cytotoxicity and accelerates effective treatment responses in patients with chronic myeloid leukemia. Front Immunol 9: 3152, 2018

73. Sanchez-Correa B, Morgado S, Gayoso I, Bergua JM, Casado JG, Arcos MJ, Bengochea ML, Duran E, Solana R and Tarazona R: Human NK cells in acute myeloid leukaemia patients: Analysis of NK cell-activating receptors and their ligands. Cancer Immunol Immunother 60: 1195-1205, 2011.

74. Rouce RH, Shaim H, Sekine T, Weber G, Ballard B, Ku S, Barese C, Murali V, Wu MF, Liu H, et al: The TGF- $\beta /$ SMAD pathway is an important mechanism for NK cell immune evasion in childhood B-acute lymphoblastic leukemia. Leukemia 30: 800-811, 2016.

75. Valenzuela-Vazquez L, Núñez-Enríquez JC, Sánchez-Herrera J, Jiménez-Hernández E, Martín-Trejo JA, Espinoza-HernándezLE, Medina-Sanson A, Flores-Villegas LV, Peñaloza-González JG, Refugio Torres-Nava J, et al: Functional characterization of NK cells in Mexican pediatric patients with acute lymphoblastic leukemia: Report from the Mexican Interinstitutional Group for the Identification of the Causes of Childhood Leukemia. PLoS One 15: e0227314, 2020.

76. Jarosz M, Hak Ł, Więckiewicz J, Balcerska A and Myśliwska J: Clinical immunology NK cells in children with acute lymphoblastic leukemia and non-Hodgkin lymphoma after cessation of intensive chemotherapy. Cent Eur J Immunol 34: 94-99, 2009.

77. Hsu KC, Keever-Taylor CA, Wilton A, Pinto C, Heller G, Arkun K, O'Reilly RJ, Horowitz MM and Dupont B: Improved outcome in HLA-identical sibling hematopoietic stem-cell transplantation for acute myelogenous leukemia predicted by KIR and HLA genotypes. Blood 105: 4878-4884, 2005.

78. Fei F, Lim M, George AA, Kirzner J, Lee D, Seeger R, Groffen J, Abdel-Azim H and Heisterkamp N: Cytotoxicity of CD56-positive lymphocytes against autologous B-cell precursor acute lymphoblastic leukemia cells. Leukemia 29: 788-797, 2015.

79. Maude SL, Laetsch TW, Buechner J, Rives S, Boyer M, Bittencourt H, Bader P, Verneris MR, Stefanski HE, Myers GD, et al: Tisagenlecleucel in children and young adults with B-cell lymphoblastic leukemia. N Engl J Med 378: 439-448, 2018.

80. Park JH, Rivière I, Gonen M, Wang X, Sénéchal B, Curran KJ, Sauter C, Wang Y, Santomasso B, Mead E, et al: Long-term follow-up of CD19 CAR therapy in acute lymphoblastic leukemia. N Engl J Med 378: 449-459, 2018.

81. Li L, Liu LN, Feller S, Allen C, Shivakumar R, Fratantoni J, Wolfraim LA, Fujisaki H, Campana D, Chopas N, et al: Expression of chimeric antigen receptors in natural killer cells with a regulatory-compliant non-viral method. Cancer Gene Ther 17: 147-154, 2010.

82. Shimasaki N, Fujisaki H, Cho D, Masselli M, Lockey T, Eldridge P, Leung W and Campana D: A clinically adaptable method to enhance the cytotoxicity of natural killer cells against B-cell malignancies. Cytotherapy 14: 830-840, 2012.

83. Xie G, Dong H, Liang Y, Ham JD, Rizwan R and Chen J: CAR-NK cells: A promising cellular immunotherapy for cancer. EBioMedicine 59: 102975, 2020.

84. Liu E, Marin D, Banerjee P, Macapinlac HA, Thompson P Basar R, Nassif Kerbauy L, Overman B, Thall P, Kaplan M, et al: Use of CAR-transduced natural killer cells in CD19-positive lymphoid tumors. N Engl J Med 382: 545-553, 2020.

85. Sánchez-Cuaxospa M, Contreras-Ramos A, Pérez-Figueroa E, Medina-Sansón A, Jiménez-Hernández E, Torres-Nava JR, Rojas-CastilloE and Maldonado-BernalC: Low expression of Toll-like receptors in peripheral blood mononuclear cells of pediatric patients with acute lymphoblastic leukemia. Int J Oncol 49: 675-681, 2016. 
86. Samudio I, Rezvani K, Shaim H, Hofs E, Ngom M, Bu L, Liu G, Lee JT, Imren S, Lam V, et al: UV-inactivated HSV-1 potently activates NK cell killing of leukemic cells. Blood 127: 2575-2586, 2016.

87. Flavell DJ, Holmes SE, Warnes SL and Flavell SU: The TLR3 agonist poly inosinic: Cytidylic acid significantly augments the therapeutic activity of an anti-CD7 immunotoxin for human T-cell leukaemia. Biomedicines 7: 13, 2019.

88. Cheadle EJ, Lipowska-Bhalla G, Dovedi SJ, Fagnano E, Klein C, Honeychurch J and Illidge TM: A TLR7 agonist enhances the antitumor efficacy of obinutuzumab in murine lymphoma models via NK cells and CD4 T cells. Leukemia 31: 1611-1621, 2017.

89. Kim H, Khanna V,Kucaba TA, Zhang W, Sehgal D, Ferguson DM, Griffith TS and Panyam J: TLR7/8 agonist loaded nanoparticles augment NK Cell-mediated Antibody-based cancer immunotherapy. Mol Pharm 17: 2109-2124, 2020.
90. Ronsley R, Kariminia A, Ng B, Mostafavi S, Reid G, Subrt P, Hijiya N and Schultz KR: The TLR9 agonist (GNKG168) induces a unique immune activation pattern in vivo in children with minimal residual disease positive acute leukemia: Results of the TACL T2009-008 phase I study. Pediatr Hematol Oncol 36: 468-481, 2019.

(i) $\odot$ This work is licensed under a Creative Commons Attribution-NonCommercial-NoDerivatives 4.0 International (CC BY-NC-ND 4.0) License. 